\title{
Monument to anti-monumentality: the space of the National Museum Australia
}

\author{
Uros Cvoro*
}

University of New South Wales, Sydney

\begin{abstract}
:
This article explores the space of the National Museum Australia as a complex interplay between different spatial levels, and the way in which this interplay enables the NMA to foreground internal tensions architecturally. I am also interested in the way these internal tensions contribute towards creating representations of spaces as politically charged. I argue that the space of the NMA should be read as riven with tension between monumental space and what I refer to as protean monumental space. The tension between the monumental and the protean monumental is always already entailed within the spatial practice and spatial representation of producing the NMA's space. This tension is internal and central to the museum itself, yet it is a tension that leads to a production of a 'third space' that is already predicated by the other two, or is revealed by the experiencing body of the museum visitor.
\end{abstract}

Keywords: National Museum Australia; museums; architecture; nationalism.

The National Museum of Australia (NMA) is decidedly and deliberately an anti-monumental space (Fig. 1). Even the scarcest glimpse of the NMA's asymmetrical, de-centralized and fragmented building makes it clear that its space intentionally sets out to undermine associations

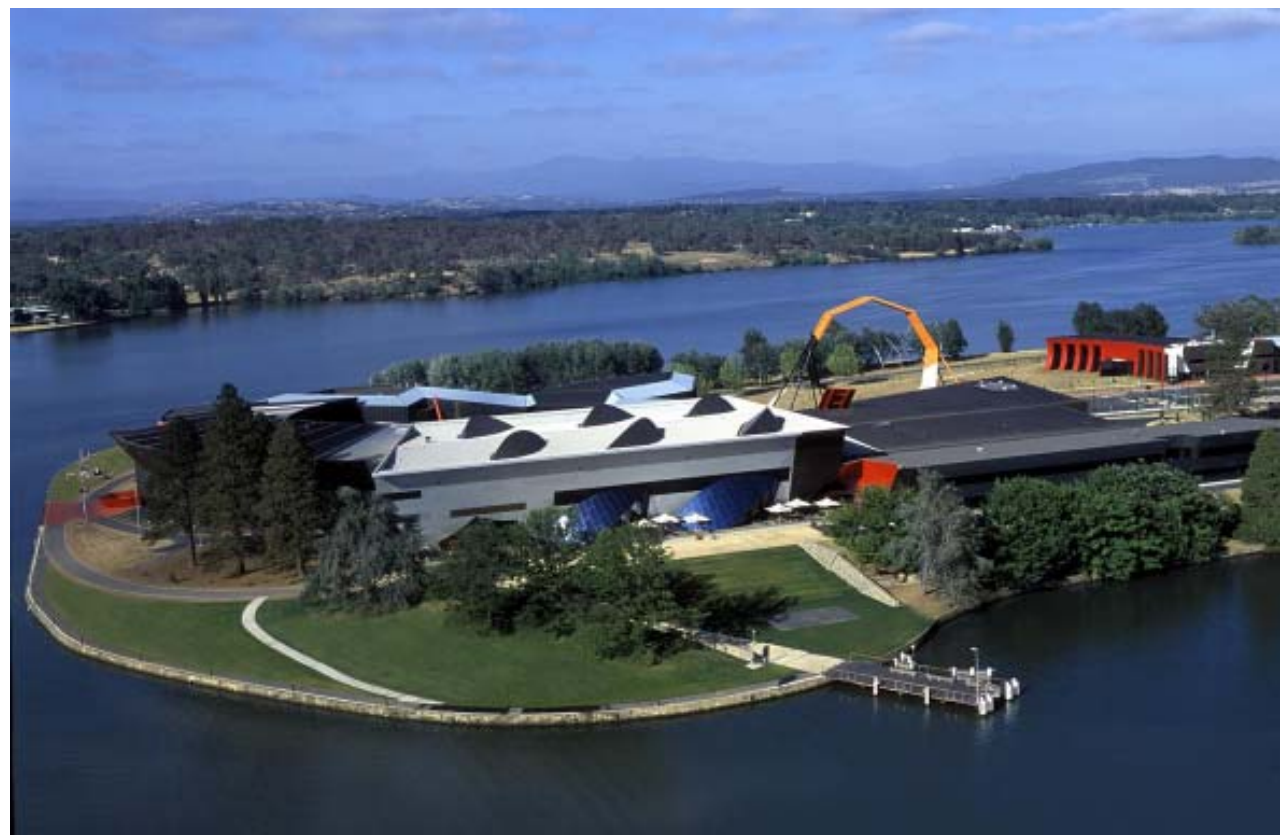

Fig. 1. The National Museum of Australia, aerial view (courtesy of the NMA).

museum and society, November 2006. 4(3) 116-128 @ 2006, Uros Cvoro ISSN 1479-8360 
with the monumental space of museums of modernity. There is no grand-archway entrance at the front of the building. There are no stern structures, neutral colours or imposing architecture. In fact, everything about the NMA's architecture starkly contrasts with grandiose architecture. Bright buildings painted in yellow, red, orange, blue shine from various parts of the NMA in a playful and casual mood. The entrance to the museum is tucked away to the left of the front of building. The great orange-red swirl of Uluru line (Ayers Rock) stretches across the front, suggesting that this may be an amusement park rather than a national institution. Metal sheet and plasterboard substitute the 'serious' materials of stone and stainless steel used for serious institutional buildings, suggesting that it may even be a trendy suburban shopping centre. The relatively small and unobtrusive building stretches out on the Acton Peninsula to form a horseshoe around the playground-like Garden of Australia Dreams. Different spaces overlap and seamlessly blend almost to the point of no distinction. The space of the NMA creates a sense of overlap between its individual galleries to the point of confusion. Yet, the sense of spatial chaos in the NMA is still somehow presented on a human scale. The building's vibrant mess looks like a product of child's imagination, unrestrained and unimposing. By bringing its space to the human scale, the NMA shows an emphasis on the way in which its space is experienced. The architecture of the NMA appears to be inviting questions, rather than presenting a clear message.

This brief description of the NMA's architecture establishes it as a space of architectural plurality and overlap. The overlap and tensions between the architectural spaces in the NMA - the Main Hall, the Gallery of First Australians and the Garden of Australian Dreams - and their relation to representation of Australia is the main concern of this essay. Using a combination of Lefebvre's and the Situationists' notion of lived experience of space, I want to suggest that the NMA can be thought as an institution that attempts to open up the monumentalism of the museum and reveal it as a space of tension. I argue that the space of the NMA should be read as riven with tension between monumental space and an alternative mode of spatiality I will propose as the protean monument. This sense of spatiality allows for a sense of movement through the museum in a manner that makes it possible for another non-monumental space of representing Australia to unfold. Yet, as I will show, the tension between the monumental and the protean monumental is always already entailed within the spatial practice and spatial representation of producing the NMA's space. This tension is internal and central to the museum itself, yet it is a tension that leads to a production of a 'third space' that is already predicated by the other two, or else is revealed and highlighted by the experiencing body of the contemporary museum visitor. I will demonstrate that the tension the NMA unleashes by refusing to resolve the opposition between the monumental and the protean monumental emerges out of its actual architectural layout, and in the combinatorial approach to its spatial elements. I will show that the way in which the NMA plays on notions of museum monumentality can be located in the NMA's location on the map of Canberra, in the way it juxtaposes architectural citations, and in the way the NMA's spaces are generated by conceptual frameworks such as the Boolean Knot to refuse surface meaning, clear-cut signs or unifying symbols of Australia.

\section{Protean monumentality}

The notion of the NMA as a protean monument shot through a complex nexus of interplaying levels of spatiality comes from Henri Lefebvre's understanding of monumentality as a 'singular spatial representation of collective identity' (Lefebvre 1991: 221), and its failure to account for the inconsistencies of the audience's 'lived' experience of space. Lefebvre argues that the contradictions of space are determined by the contradictions of the society, which are experienced and reshaped through our 'lived' experience of space. Lived space is directly experienced through thinking, walking, talking and observing it. It is lived in the contact between the way in which private experiences are expropriated into space, and the way in which the experience of space is appropriated into private experience. The ability of lived experience to resist complete recuperation into dominant ideologies is of crucial importance for my consideration of the space of the NMA. According to Lefebvre, monumental space fails its purpose because it can never completely absorb all aspects of spatiality and its internal tensions and conflicts into 
a singular representation of space. In attempting to accommodate the diversity of lived experience, monumental space imposes an illusion of permanence that attempts to transcend time. The monument creates the illusion of permanence by substituting the conflictual tensions of actual space with a 'materially realised' appearance of space. (Lefebvre 1991: 221) Yet, this appearance of space can never fully account for the inconsistencies of the lived experience of space. In part, this is because monuments represent space as something that is to be 'read' whereas, lived space for Lefebvre should be experienced.

In this respect, the proximity of the protean monumentality to the spatiality of everyday life is related to the spatial strategies of dérive and détournement developed by the Situationist International. The Situationists spatial practices asserted that creative and spontaneous activities - such as walking, speaking and looking - maintained a connection to the everyday life that could never be co-opted into the capitalist hold over space. (Gardiner 2000: 122) The protean monumentality of the NMA should be considered as the combination of the spatiality that emerges from the strategies of dérive and détournement.

According to Guy Debord, the derive, literally meaning 'drifting' in French, is a strategy of spontaneous passage through space without prescribed duration or spatial field. (Debord 1996: 22) Two key aspects of derive's spontaneity should be pointed out: dérive is a strategy of re-creating displacement in an environment that can be on the one hand a playful and intentional exercise of trying to lose yourself through drifting; yet, on the other hand dérive is also about recreating the displacement felt in a foreign space, such as the experience of an (illegal) immigrant or a 'culturally non-initiated' visitor to the museum. In terms of the NMA then, the dérive has a doubling function between purpose and possibility. The purpose suggests intentional undoing of the monumental structure of the museum through movement that would, for example, not follow its set spatial narrative. The possibility refers to the dérive as focused on a particular kind of urban spatiality, based on large European metropolitan centres such as Paris and London, and in contrast to the carefully designed open spaces of Canberra. If dérive is, as much about what and who is encountered while drifting as it is about the act of drifting itself, Canberra's planned urban space severely limits this possibility. Anyone who has ever visited Canberra's carefully structured and manicured urban space will be aware of the almost complete absence of people (and traffic) and of the impossibility of getting anywhere by walking. Canberra's centralized urban landscape where all the roads lead to one central point - the Parliamentary triangle, the legal and administrative centre of Australia - effectively pacify and sanction the dérive as an activity of urban guerrilla nomadism. Yet, dérive as a strategy is always about the undoing of precisely carefully constructed and ordered spaces through the movement, or the act of drifting. This then creates a tension between the near impossibility of the dérive in Canberra's space against the created setting of the NMA that almost promotes drifting. Or, rather it creates a contrast between the purpose of the dérive as an activity that is encouraged by the spatial outline of the NMA's space, and the possibility of the NMA taking place in Canberra's urban space (intentionally designed to prevent such activities).

The second Situationist strategy related to the NMA's protean monumentality is the practice of transforming of cultural products and representing them within new artistic contexts: 'Détournement, the reuse of preexisting artistic elements in a new ensemble.' (Ford 2005: 36) The détournement is both the practice of hijacking of cultural material - such as advertisements, photographs, images, objects, slogans and buildings - and rearranging of that material for the purpose of ideological criticism. The creative plagiarism and the deliberate mixing of sources with disregard for the distinctions between 'low' and 'high' entailed in the détournement (Sadler 1999: 18) is axiomatic to the eclecticism of postmodernist architecture, of which the NMA's space is exemplary. As a set of aesthetic and spatial strategies, where elements are indiscriminately taken and mixed to construct certain representations, the détournement here refers to the way in which the overall structure of the NMA constitutes a re-assembling of history in the viewer's experience of the juxtaposed spaces.

Using a combination of Lefebvre's and the Situationists' notion of lived experience of space, I want to suggest that the NMA can be thought as an institution that attempts to open up the monumentalism of the museum and reveal it as a space of tension. If we take the monument as the intersection of 'public art and political memory', as James Young puts it (Young 2000: 93) then the NMA can be poised spatially at the intersection of the monument and 
experience. On the one hand, the monument will represent the space of the nation represented through political and public memory. On the other hand, the flux of the space of the NMA will represent the personal, lived experience of the viewer. Yet this is not an 'undoing' of the monumental space in the NMA in the sense of a negative movement. Instead, the protean monumental space in the NMA develops within the monumental through everyday, lived spatial practices.

I want to advance protean monumentality as a notion of museum space via the NMA, and in contrast to the existing understandings of museum space. The field of studies of museum space is very diverse and ambiguous, and its survey is beyond the scope of this essay. It is sufficient to say that while critical studies of museum space do exist, their approaches differ based on their originating discipline - whether it is philosophy, cultural anthropology or sociology - and create a multitude of theories applied to museum space, ranging from museum as a 'heterotopia', 'folded' space, museum as gendered space, museum as space of cultural contact, museum as space of fairs or carnivals, museum as civic space of social ideals and museum as space of consumption. Yet despite the apparent abundance of architectural histories of museum space, a systematic account of the philosophical implications of contemporary museum space such as the NMA is still missing. This is at least in part because a number of contemporary museum spaces such as the Main Hall of the NMA have been produced through computational renderings of space in ways that shift the traditional perspectival and material arrangement of space to the dynamic spatiality of the information and representation (Virilo 1998: 180). Spaces such as the Main Hall lack statically ordered perspectival arrangement, giving the effect of constant movement. Their architecture provides multiple frames of overlapping space between layers of visible material space and invisible computational space leaving a sense of dynamic spatiality.

\section{The tense space of the NMA}

It is of no surprise that the NMA has become the focus of close scrutiny on the subject of its architecture following its opening in 2001. Scores of reviews debated the building and space of the NMA focusing on the questions of the particular use of digital technology in modeling elements of its space. Heated arguments drew attention to the range, extent and political implications of its numerous architectural citations (Windschuttle 2001: 11-19). The NMA was hailed by some to be the epitome of a postmodern approach to architecture and was even awarded the prestigious Blueprint Architecture Award for the World's Best New Public building of 2001. At the same time it was criticized by others as not appropriate for a national museum (Frith 2001: 13). Yet despite some interesting discussion of the NMA's building, these arguments stubbornly focused on simplistic questions such as whether the NMA was appropriate as a national museum or whether it was a museological 'theme-park'; whether its easy-handed approach to national history served the educational interest of the public or simply played with the clichés of Australian history. What was overlooked were precisely the questions concerning the tensions that the NMA intentionally unleashed by refusing to resolve these oppositions in its actual architectural layout and in the combinatorial approach to its spatial elements.

Naomi Stead's discussion of the NMA provided one of its more perceptive readings, identifying its architecture as an expression of tensions and indeterminacy that already exist both in Australian identity and the idea of a national museum (Stead 2002: 121-135). Stead argued that the NMA employs a strategy of 'populism', using a 'playful and obtuse' aesthetic and architecture that invites identification and interpretation by the visitor only to present them with a series of unresolved tensions. Her intention was to both suggest an interpretation of the NMA and to problematize the predominant ways of reading the NMA along the division between education and entertainment. Stead suggested that the dialogical quality of the NMA's space endowed it with a subversive potential that could escape both simplistic readings and provide insight into the present condition of Australian nationalism. Stead's discussion of the tensions between different meanings of the NMA identified what I take to be the crucial point about the way in which its space brings internal tensions to the fore and provides a framework for unpacking of larger questions. She argued that the NMA's 'popular' look was an intentionally produced appearance through aesthetic devices such as bright colour, figurative elements, 
visual jokes, and non-quadratic forms. This appearance of the NMA invited the interpretations of its architecture as populist with its negative connotations of crassness and appealing to the lowest common denominator. However, despite such accusations by many reviewers, the NMA was simultaneously identified as confusing and alienating to its visitors, where its meaning was somehow being lost in the architecture. This paradox of the NMA entailed that despite its popular look, because its meaning was much more difficult and challenging to grasp, the NMA was looking popular but was not being popular enough.

Stead's articulation of the paradox that the NMA's space occupies with respect to the various interpretations of it is of special significance here. I want to argue that her discussion is suggesting that the tensions that we bring to the space of the NMA through interpretations may already be predicated in the space itself. These tensions are apparent in discussions of the distinction between 'populist' and 'popular' in the NMA just as they are in distinctions between 'monumental' and the 'anti-monumental' space in the NMA. Her article briefly reflects on the distinction between 'monumentality' and 'anti-monumentality' in the NMA to suggest that a similar tension may be at work. I want to explore this point further in this essay to propose a reading of the NMA's space as an attempt to open the monumentality of the museum to its internal tensions through playing with certain oppositions that inflect our understanding of museum space. I want to suggest that the NMA raises the issue of a relation (rather than exclusion) between monumental and protean monumental museum space. My argument will be based on the premise that the two are always already predicated by the other through a 'third space' that resides in the tension produced between them. This third space is a space of irresolvable tensions that is only made apparent through the experience of the visitor to the NMA.

\section{From the monumental to the protean monumental space of the NMA}

The open-handed approach of the NMA's architecture has been identified by a number of critics as inappropriate for a national institution. The NMA's approach to national identity was seen by many to lack pedagogical rigour or strength. The fact that this museum invited questions rather than provided the answers was identified as its main detraction. Yet, despite the large number of complaints, nothing about the NMA should be surprising. The architectural brief for the building of the NMA only kept in line with the Piggott Report's recommendations from 1975, which emphasized that the museum should be an anti-monumental building without a grand entrance (Piggott 1975). On the one hand, the space is unobtrusive and unimposing, inviting identification and participation from the audience. This would suggest that its architecture embraces the new museology driven shift towards more open and democratic architecture. Yet, the architecture of the NMA is incomprehensible to its visitors. It is impossible to relate to the space of the NMA on a human scale, or comprehend its overall meaning on the first encounter. Its spaces are far beyond the common sense experience of museum space. In order to grasp the meaning of spaces like the Main Hall or the architectural reference to the Jewish Museum Berlin in the outline of the Gallery of First Australians, we require access to the bird's eye or aerial view of the building. The NMA thus symbolically gives access to its meaning only via the remote view from above, or the informed architect's eye looking at its blueprint. However, even if this view is granted there is no guarantee of grasping its meaning, because what is required is a three-dimensional model of the NMA's Main Hall in order to grasp it conceptually. The overall architecture of the NMA both invites and negates the monumental.

The debate over whether the NMA was to be regarded as monumental originated in the criticism over the choice of Canberra's Acton Peninsula as the site for the museum (Gore 2002: 250). Originally planned as a much larger (monumental) institution in the Yarramundi Reach south of Canberra, the NMA was moved to Acton Peninsula due to budget cuts, tourismoriented concerns over accessibility, and partly to keep faith with the plans for the city of the American architect Walter Burley-Griffin (1876-1937) The resulting building was decidedly much less impressive or monumental. The relocation also entailed that the museum be moved closer to the political centre of Australia and integrated into the carefully constructed and tailored landscape of Canberra. Yet, despite the shift in site, the NMA's location in the planned civic landscape of Canberra remains 'symbolically decentred' (Messham-Muir 2003: 80). I want to 
argue that this is primarily due to the way in which the NMA presents its space as both monumental and anti-monumental.

The NMA's location on the map of Canberra is exemplary of the way the museum embodies tensions. Canberra is an artificial creation of urbanism, built strictly according to designs by Walter Burley Griffin, and renowned for its docile and sedate atmosphere. The city itself almost functions as a monument to Australian institutional power, being largely built around various Federal administrative centres. At the core of Canberra is The Parliamentary Triangle, an equilateral triangle between Parliament House, Canberra's civic centre and the Department of Defense complex. The Parliamentary Triangle is Australia's political and institutional heart that symbolizes, 'the cornerstones of participatory democracy, military power and citizenry' (Messham-Muir 2003: 80). The Australian War Memorial, NMA's symbolic predecessor for almost a century, is also a part of the triangle, connected via a long boulevarde which cuts symmetrically through the centre of the triangle to the flagpole on the top of the new Parliament House.

The position of the NMA is close to, yet removed from, the Parliamentary Triangle. The NMA occupies the space of Canberra, the monument to Australia's national institutions, and at the same time is removed from the symbolic core of the Parliamentary Triangle. While associated with Canberra, the NMA can never completely be a part of its symbolic axis. The museum exists within a third space both inside and outside of Australian institutional power, a space that is predicated by the two and yet never apart from them. This is a space defined by a tension between two different conceptions of national identity articulated through national institutions. The symbolism of the NMA's location is highlighted by the fact that that it is not connected by roads or clear line of sight to the Parliament or the War Memorial, and possibly even if its were, the aesthetic differences would still set it apart. The building seems intent on remaining as the 'eyesore' of Canberra's sedated landscape.

Yet at the same time, the NMA does invoke a sense of monumentality through its architecture. However, this is a highly 'codified' and self-reflexive monumentality of aesthetic references to various architectural landmarks, accessible only to the initiated eye. The NMA is full of references to influential figures in architectural history such as Walter Burely Griffin, Aldo Rossi, Le Corbusier, James Stirling and Daniel Libeskind. In this sense, the NMA is a continuation of the practice of its designers ARM (Ashton Raggatt McDougal) both in the extensive usage of references and the ways in which they are employed. The NMA's recalling of certain buildings is not simply an exercise in postmodernist architectural referencing but is positioned against symbols of key events and figures in Australian history. It is a comment on both what these symbols represent for Australia, and what museum architecture means in general.

Museum architecture has always been the subject of great significance however it has gained even more prominence recently where almost every 'signature architect' of the twentieth century has designed a museum: Daniel Libeskind's Jewish Museum in Berlin (JMB), Frank Gehry's Bilbao Guggenheim, Rem Koolhaas' Kunsthal in Rotterdam, and Los Angeles' Getty Museum by Richard Meier. These buildings have become monuments to both collective ideals they seek to embody and to expressions of architects' pretensions to celebrity. The NMA plays on these notions of museum monumentality and architect stardom by juxtaposing these citations against each other as if they were a riddle for architectural theorists. Yet, the very fact that these references remain out of reach of the majority of NMA's visitors, also perpetuates a sense of architectural supremacy and grandeur. However, even if we accept this, the way in which the NMA reworks architectural monuments refuses their monumentality. Their form, shape and meaning is codified and integrated into the structure to such an extent that it almost disappears. This dislocates their ability to function as isolated and universal symbols of monumentality. The JMB no longer functions as the universal symbol of Holocaust memory when it is reproduced in The NMA but becomes a barely recognizable allusion to a traumatic event that may also then be associated to similar traumatic events in Australian colonial history. Le Corbusier's Villa Savoye, the epitome of architectural modernism, becomes a blackened Indigenous cultural centre rendered to appear as the mask of Ned Kelly. Utzon's Opera House's iconic global status gets reduced to a series of references through shell-like windows on the ceiling of the NMA's Main Hall. 


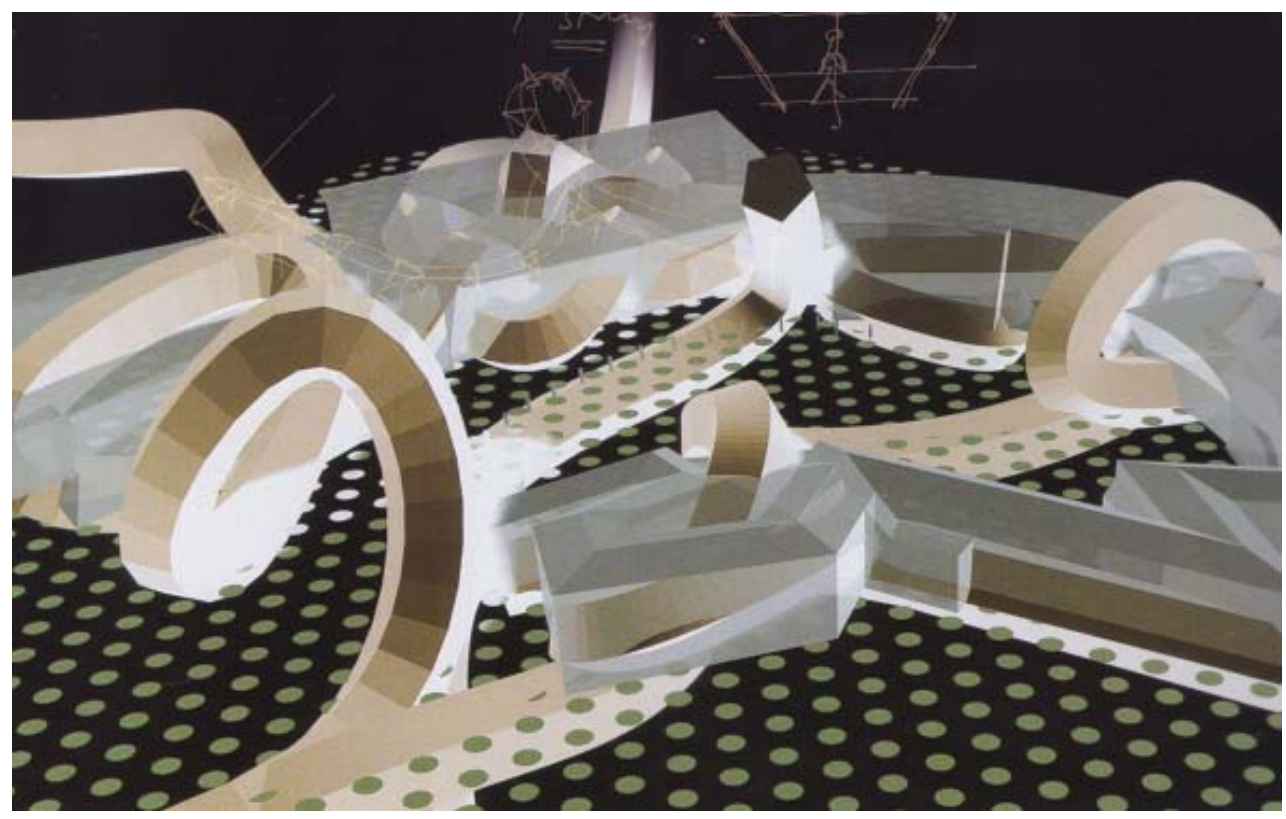

Fig. 2. Diagram of the Boolean Knot intersecting with the National Museum of Australia (courtesy of Howard Raggatt)

Yet none of this is explicit. The NMA's spaces are constructed in a way that refuses surface meaning, clear-cut signs or unifying symbols. The NMA's architect Howard Raggatt suggests that the museum is a symbol of 'tangled destinies' (Raggatt 2002: 32). This is exemplified by the way the NMA's space is constituted around a Boolean Knot, through a series of threads that knot together inside the Main Hall and then cut through some of its buildings. The NMA's Main Hall is a monument to Boolean geometry, yet this is beyond the visitor's conceptual grasp unless they are equipped with a three dimensional image of the space. The Main Hall thus provides a basis for two different understandings of space, between the Boolean knot and digital architecture and the Opera House and representational referentiality.

The space of the NMA is generated - rather than designed - by the framework of the Boolean Knot. The Boolean Knot takes its name from Boolean geometry, which is a system of 'articulating logical statements symbolically' developed by an English mathematician George Boole. Boolean geometry refers to the sets of relations between objects in terms of their 'unions' and 'differences', which can be translated into three basic functions, 'and' 'or' and 'not'. Boole's binary approach could also be applied to form objects by cutting one shape into another. Raggatt translated this system into architecture as a way of articulating built form through sets of relations between volumes. (Raggatt 2002: 32). Boolean architecture combines different three-dimensional elements to generate space from the subsets defined by their union, intersection and complementation. In the NMA, six threads are tied together and cast into a fivesided extruded shape to produce the Main Hall. One of these threads cuts through the building volumes, producing the red 'incisions' on the surface of the NMA, and articulating the sculptural loop in front of the building. The Boolean Knot performs a two-fold function: firstly it is a reference to the American architect Walter Burley Griffin's 1912 design for Canberra, which is governed by geometrical axes, one of which crosses the NMA's location Acton Peninsular; and secondly it works conceptually to entwine the various narratives in the NMA's exhibitions. The Boolean Knot tangles together Griffin's axes, adding another that extends to Uluru, the Aboriginal name for Ayers Rock, a large rock formation in Australia's Northern Territory that holds great spiritual significance. The 'Uluru axis' articulates the loop in front of the NMA and continues past the AIATSIS (Australian Institute of Aboriginal and Torres Strait Islander Studies) building, springing back like a cord under tension. This axis articulates an encounter between two 
conceptions of Australia, one suggested by the Parliamentary Triangle and the other by the vector towards Uluru. This suggests that the Boolean Knot may be a space of encounter between two very different conceptions of Australian identity, one articulated through Aboriginal understandings of country and people, and the other through a non-Aboriginal understanding of political community. The Boolean Knot also ties together the heterogeneous narratives of the NMA into the indeterminate space of the Main Hall.

\section{The Main Hall}

The Main Hall is the first space that visitors encounter upon entering the NMA. (Fig. 3)The Main Hall spatially articulates the main themes of the NMA, setting the stage for the galleries that follow. The space of the Main Hall is articulated by the computational Boolean Knot, suggesting that Australian identity is constituted by bringing together diverse stories. Yet, the knot is computational and it is left up to the visitors to articulate it through their experience as they navigate the open space of the Main Hall. The inverted form of the Main Hall problematizes the way in which its space is experienced. The only way in which we can grasp the meaning of the space is from an aerial shot, and even in this instance, the meaning is denied because we need access to a model of its three-dimensional space. As the NMA's architect Howard Raggatt explains, the reversal of space in the Main Hall is an expression of the ambiguity that is at stake in defining the relation between visible and invisible space:

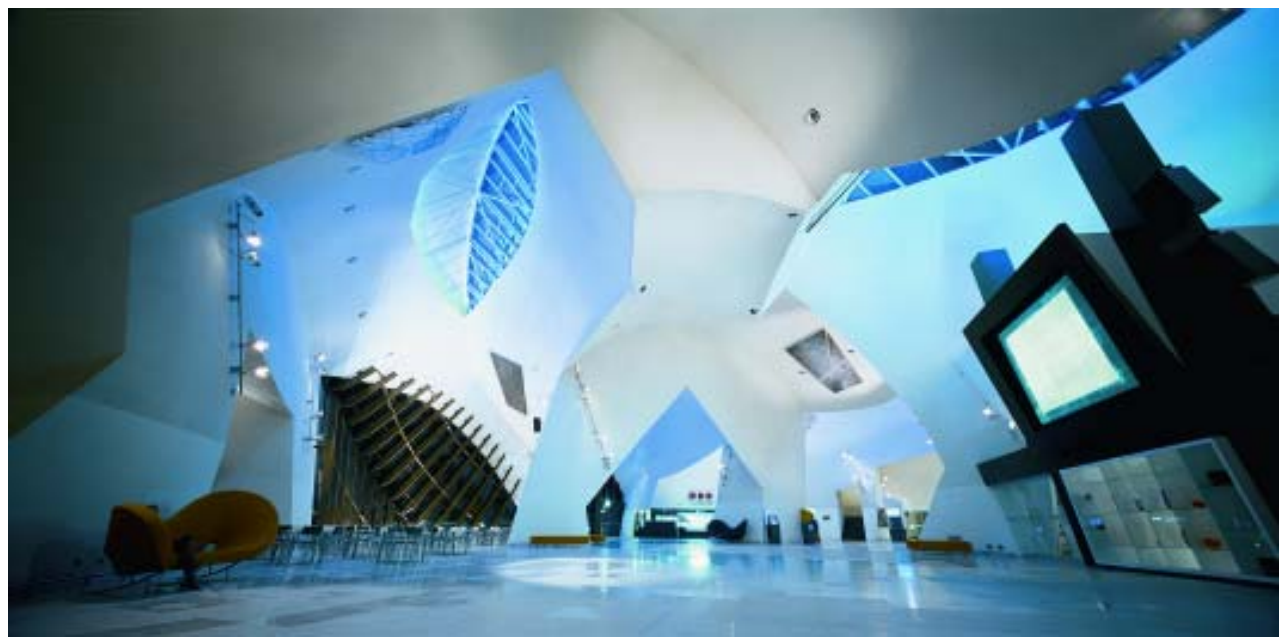

Fig. 3. The Main Hall of the National Museum of Australia (courtesy of the NMA)

...the hall cast declares the oscillation between the visible and the invisible, or between absence and presence. It is now an object of continuous expectation, perpetually an object of hope, but also empty. It is an object of intense waiting, or an object of special postponement and delay, a space still always longing, a space which never claims self satisfaction or sufficiency (Raggatt 2002: 35).

The architecture of the Main Hall operates through three levels of interaction between visible and invisible space: computational and physical (computational geometric shape projected onto material space); object and cast (negative impression of space imprinted into the positive space); experiential space and conceptual space (experiencing the space without fully comprehending its meanings). These levels of interaction suggest a complex interplay between different levels of space, and I will explore each here.

The Main Hall is a cast of a computational knot, created by a spatial subtraction of a computer-rendered from a physical form. As much as it is a symbol of 'tangled unity', this knot 
is also created by tangling of separate and different strands. The computational knot represents the unison and the tension between them. The principle of knotting is based on a tension between the different strands holding them together. In fact, the loosening of these tensions would lead to the disentangling of the threads and mark the undoing of the knot. Therefore the Main Hall holds together disparate elements, such as the Uluru line and the lines of Canberra's political grid, and generates its meaning from the tensions between them. It does not present a fixed meaning, but allows the visitor to unfold them through their own experience. Furthermore, this is a computational knot and in order to grasp its meaning (or attempt to disentangle it) we must imagine it as a whole that is constituted by many different parts. Yet, this whole never existed in an 'untangled form', so there was and can never be an a priori form of the knot. The way in which the Main Hall positions computational and physical space plays on our understanding of the relations between ideas and material forms. That it has no discernible meaning outside the virtual, and furthermore that this meaning is out of reach is also a comment on the impact of new technology on perceptions of space. The essential form of the Main Hall is computerproduced and its abstract space is most likely to be comprehended by a younger audience that is attuned to digital spaces.

In terms of the relation between object and cast, the space of the Main Hall enacts a three-fold play of signification. First, the space of the Main Hall is a cast. In the traditional process of casting, where objects are derived from a material cast, they carry an indexical relation to the original. In other words, there are always irreducible traces of the original object present in the cast. In the case of the Main Hall, the original object was a computational (non-material) space, so that effectively there are no material traces to be seen on the cast. Because there are no traces, the material indexical relation is undermined. However, the design for the cast of the Main Hall may be computational, yet it derives its form from rope, which was used as a tool during the design stage (Raggatt 2002: 99). So the initial casting was in fact a double process of casting. The form of the computational knot was derived from a material object that was then translated into a computational form of a three-dimensional knot. Finally, the actual physical space of the Main Hall was generated as the negative space of the computational modeling of the knot. In fact, the last stage is a negation of the process of casting because casting in most cases entails the destruction of the original (or rather the copy of the original object which is used for the process of casting). In this case, there is no original and there is no cast outside the computational space. The space of the Main Hall is effectively the left-over negative space from a computational cast which never existed, and which was derived from a material form. Thus, the space of the Main Hall unpacks the binary of the negative and the positive space entailed in the process of casting through a complex interplay of relations between object and cast.

In terms of the relation between conceptual and experiential space, the Main Hall is both an invitation and a rejection of the visitor's body. It refuses an immediate identification with the space through familiar structures or shapes, inviting a process of identification on the part of the visitor. However, this process can never be complete, because it is impossible to identify with the space of the Main Hall on that level. Its difficult meaning is beyond the grasp of the audience if they don't have access to aerial views or architectural plans. The fact that a different kind of experience of space is required to fully grasp the meaning of the Main Hall, suggests it as a place of re-inscribing the viewer. Its space exists between two experiences. This space refers to the viewer's lived experience of the Main Hall. It involves the immediate reaction to its physical space. This may include walking or drifting through that space, solitary interaction with the space, or social interaction with the space through shared experience with other people present. This space also refers to the viewer's coming to terms with the computational nature of this physical space that is beyond the grasp of the immediate lived experience. It includes the conceptual or mental space of the viewer that is wedged between the computational cast and the physical space, the invitation that is presented by the open space of the Main Hall and the rejection that is entailed in its resistance to easily identifiable meaning. I would argue that should be positioned in the uneasy experience of the Main Hall - reported by a number of my students - that dwells between these two layers of spatiality. 


\section{The Gallery of First Australians}

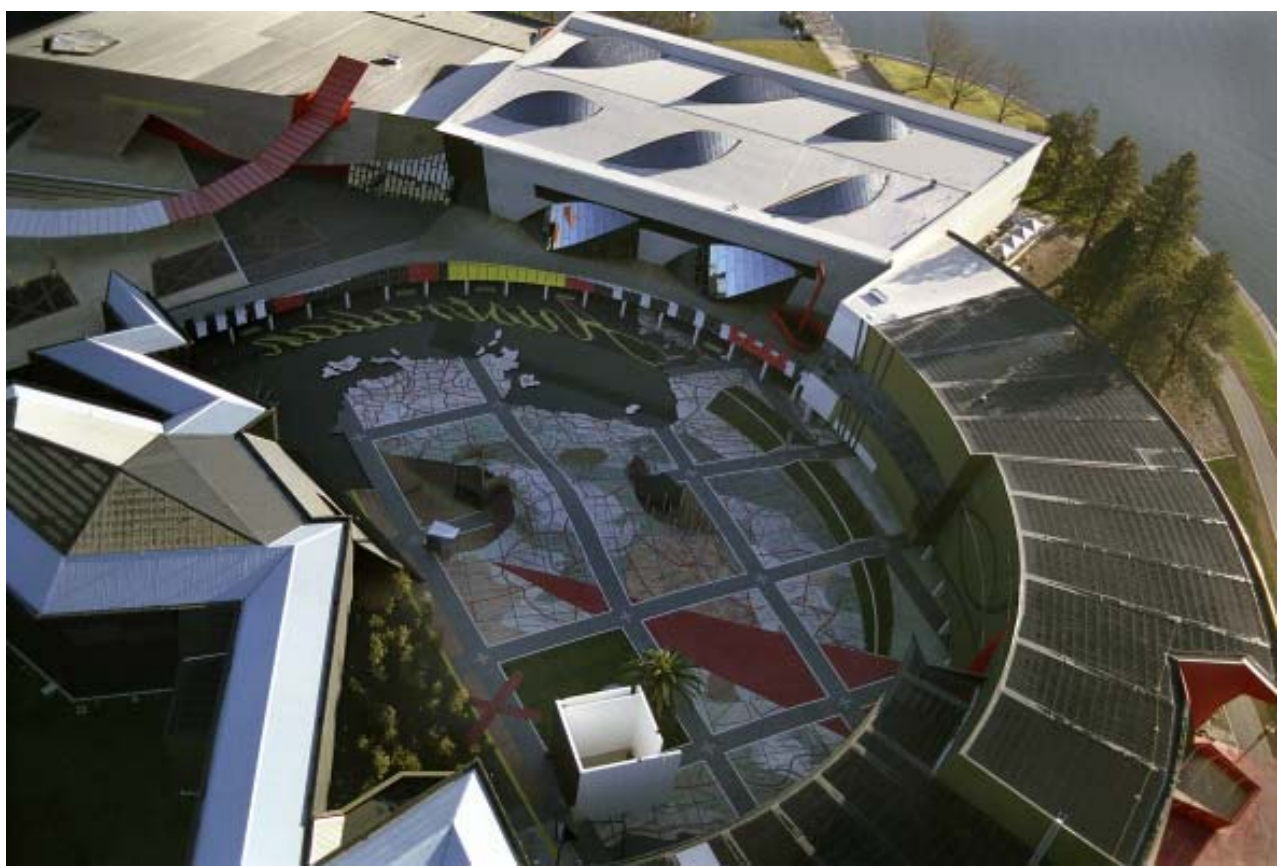

Fig. 4. The Garden of Australian Dreams, and the Gallery of First Australians [left] (courtesy of the NMA)

The Gallery of First Australians (GFA) is the last space encountered in the NMA (Fig. 4). It is located across from the Main Hall, separated by the Garden of Australian Dreams. The space is dedicated to Aboriginal and Torres Strait Island culture. In contrast to the other spaces, the Gallery is separated from the rest of the museum, and entered through a corridor. In this corridor is the multimedia installation Welcome Space, which serves as a symbolic initiation into the space. The degree of separation between the space of the GFA and the rest of the NMA is also present in the tone of the exhibition, where a much more serious tone prevails in the GFA. The GFA uses the form of Daniel Libeskind's JMB through a 'built shadow'. Here the JMB casts a shadow across the GFA, which is then enclosed in a volume. Interestingly, the reference to the $\mathrm{JMB}$ is only visible to people familiar with the building and who access aerial views of the NMA. The NMA's Gallery of First Australians differs from the JMB in appearance, size, materials and internal organization.

The GFA's reference to the JMB unsettles the Australian colonial myths by 'thematising the barbarism' inherent in those myths (Moses 2001: 108). The reference does not suggest a picture of an 'Australian Holocaust' despite some of the claims made by its conservative critics (Pearson, 2003: 20). Instead, the way in which the GFA's space references the JMB is by insisting that the Holocaust is distinctively different to colonial genocide in Australia. However the aspirations to 'progress' and 'civilisation' that created similar nationalist ideological motivations for both events implicates them in the same historical process. The zigzag shape of the space orients the representation of Aboriginal history towards this shared historical direction while not imposing the stamp of Holocaust memory. The Holocaust is thematically present in the reference but this is not made apparent. To be aware of the reference - and thus frame our understanding of Aboriginal history through links to the Holocaust requires additional inquiry into the nature of representations of Aboriginal history. 
The reference to the Jewish Museum thus does not function as a homogenising seal of trauma that overlays the whole Gallery. The intertextuality between the spatial typology of the building and other 'hints' in the GFA, such as the huge black cross and background whispers and weeping audio recordings, merely suggest the links. They imply that not only do notions of historical progress depend on events like Holocaust but also that debates currently taking place over the nature of history in Australia are part of the same legacy that produced both colonial genocide and the Holocaust. Yet, while the space of the GFA questions colonial expansion and violence in Australia occurring in the name of progress, it insists that this is not the only way to interpret history. Rather, it insists that the history of European colonisation in Australia is as much a document of barbarism as it is a document of civilisation. It makes us aware of the tragedies that form our history, but incorporates them within that history as one of the 'multitude' of other histories, such as survival, resistance and co-operation.

\section{The Garden of Australian Dreams}

The Garden of Australian Dreams (GOAD) is the central open space of the NMA around which the museum forms a curve with the Main Hall and the GFA as the end points. Topographically, it is the most complex space in the NMA. It is essentially a concrete surface map of Australia densely layered with levels of information upon which visitors can walk. The space interweaves, overlays and juxtaposes two main maps: the Standard English language map of Australia and Horton's map of the tribal boundaries of indigenous Australia which includes over 300 boundaries. Other information on the surface of GOAD includes vegetation maps, geology maps, electoral boundaries, exploration maps, road maps, the Dingo Fence, and a weather map taken from Australia Day 1998. The word 'Australia' copied from a five dollar note in reverse is written large half in and half out of the water at the northern end of the garden. The Word 'home' translated into various languages spoken in contemporary Australia is written in various places on the surface of the map. In the middle, the map rises to form a dark tunnel, at one end of which is a camera obscura designed from the front to resemble the armour of Ned Kelly. The design references both the powerful Australian iconography of the outback outlaw and Sydney Nolan's painterly depiction of it. Other references to renowned Australian artists such as Arthur Streeton, Arthur Boyd and Gordon Bennett abound in the Garden

The GOAD is also intended as a reflection of the themes that are explored within the NMA. The overall concrete map of the Garden is a reflection of the map of Australia in the Imaging The Country multimedia display. Both maps are similarly densely layered with information, and both present a simulacrum of Australian iconography. Themes of suburban life explored in the Nation gallery are echoed in the Garden through the allusion to the suburban ideal of having a garden or a front lawn in the quarter-acre block of land in the Garden (Walliss 2004: 117). Indigenous stories of dislocation and dispossession evident in the Gallery of First Australians are referenced physically and symbolically in the dead native tree located in the water of the swimming pool of the Garden.

The GOAD thus uses its rich symbolism to articulate an idea of encounters between different understandings of land and landscape Australia. The name itself suggests an encounter between two Australian 'gardens' and 'dreams'. One is inextricably linked to notions of property, land ownership and acculturation of the land. The other represents the inscription of powerful mythology into the land. One is a reflection of Australian land defined through skate parks, Cricket Grounds, suburban gardens and parking lots. Its commentary on a relationship to high culture is also reflected in the eight blue poles located in the back of the garden behind the empty and white 'Dream home'. The poles recall Jackson Pollock's painting 'Blue Poles' and the cultural controversy that ensued following its purchase by the Australian Labor Government for the National Gallery in the early 1970s.

Yet, the most important encounter that GOAD suggests is between Aboriginal and nonAboriginal Australia. The space connects the NMA and the GFA and the different relationship to land, place, cartography and 'dreaming' that they represent. This is evident in two main examples. One of the signatures that GOAD's map bears is Edmund Barton's, Australia's first Prime Minister. It is written at the end of a large red ' $X$ ', which is the symbol that was used by many Aboriginal people to sign documents in the early days of the colony. Also, in the middle of the mapped surface is a well-maintained area of grass, a small swimming pool and a palm tree. This tree is juxtaposed against the dead native tree in the water of the pool. 
The spatial articulation of the general themes of the NMA in each of the individual galleries I discussed in this essay creates a powerful context for experiencing of the inherent tensions in the idea of Australian nation. Using a combination of Lefebvrian and the Situationists' understandings of lived experience of space, I proposed a notion of protean monumentality to explain the way in which the NMA as a whole and its individual galleries - the Main Hall, the Gallery of First Australians and the Garden of Australian Dreams - dislocate stable meaning associated with 'stable' structures such as a national museum. Even from the outset, it is spatial dislocation of monumentality that is at heart of the location of the NMA, close to yet removed from the Parliamentary Triangle - the symbol of political and administrative Australia. As I showed, such multi-layered spatiality is further echoed in the individual spaces, such as the Main Hall and its ambiguous layers of space lodged between the categories of absence and presence, object and cast, physical and computational space. In the GFA, this sense of space is used to juxtapose radically opposed representations of Australia. This complex spatiality underlines the overt complexity of the GOAD's articulation of different encounters with what it means to be Australian.

Further, as I demonstrated, these individual spaces are only meaningful in the sense in which they relate to the overall premise of the NMA, reflected in the intentionally difficult Boolean Knot. And looking at these spaces as parts of the NMA as a whole, this essay has showed that the individual spaces add up to a universal message of the NMA, but precisely that they add up to a protean space of shifting and contradictory messages that do not give-in to an easy representation or reading of Australian identity. However, this very multiplicity and complexity of meanings, scale and spatiality in the NMA then raises the question of communication between the museum and the public; whether the audience should know (or care) about its architectural representational aesthetics? After all, the NMA is a national museum, intended to present a picture of Australian national identity. Yet, as I have demonstrated, its spatial representation should - despite its overbearing presence - be only seen as complimentary to the rest of the collection in highlighting the lack of a central conception of national symbolisation and identity. That the NMA presents its space in an intentionally indeterminate and ambiguous way seems only appropriate in that these spaces reflect and re-enact the tensions that have shaped not only the history of the NMA but the history of the Australian nation as a whole.

\section{References}

Boole, G. (1951) An Investigation of the Laws of Thought: On Which Are Founded the Mathematical Theories of Logic and Probabilities. Dover Publications, New York

Debord, G. (1996) 'Theory of the Derive' in Theory of the Derive and Other Situationist Writings on the City (Ed) Andreotti, Libero and Xavier Costa Museu d'Art Contemporani de Barcelona, Barcelona

Ford, S. (2005) The Situationist International - A User's Guide, Black Dog Publishing, London

Frith, S. (2001) 'A Monument to Lost Opportunity' Canberra Times, March 20

Gardiner, M. (2000) Critiques of Everyday life, Routledge, London and New York

Gore, J. M. (2002) 'Representations of History and Nation in Museums in Australia and Aotearoa New Zeland - the National Museum of Australia and the Museum of New Zeland Te Papa Tongarewa' ,University of Melbourne: Melbourne

Hamann, C. (2001) 'Enigma Variations - the National Museum of Australia and the Aiatsis Centre' Art Monthly, (138) 5-7

Lefebvre, H. (1991) The Production of Space (Tr) Donald Nicholson-Smith, Blackwell Publishers, Cambridge 
Macarthur, J. (2001) 'Australian Baroque' Architecture Australia 90 (2) 48-61

McCulloch-Uehlin, S. (2001) 'Making an Exhibition of Ourselves' The Australian, 13 March

Messham-Muir, K. (2002) 'Here We Are! National Museums of Postcolonial Australasia in a Post-Nation-State World' World Literature Written in English 39 (2) 71-83

Pearson, C. (2003) 'Designs on History Derided' The Australian, 26 July, 20

Pigott, P.H. et al., (1975) Museums in Australia 1975: Report of the Committee of Inquiry on Museums and National Collections, Australian Government Publishing Service, Canberra.

Raggatt, H. (2002) 'Visible and Invisible Space' in Tangled Destinies: National Museum of Australia (Ed) Dimity Reed, Images Publication, Canberra

Sadler, S. (1999) The Situationist City, The MIT Press, Cambridge, Massachusetts

Stead, N. (2002) 'In the Vernacular: On the Architecture of the National Museum of Australia', Journal of Australian Studies (79) 121-135

Virilo, P. (1998) 'Architecture in the Age of Its Virtual Disappearance: An Interview with Paul Virilo by Andreas Ruby, Paris, 15 October 1993' in The Virtual Dimension: Architecture, representation, and Crash Culture (Ed) John Beckmann, Princeton Architectural Press, New York 179-187

Walliss, J. (2004) 'Garden without a Destiny: Untangling Landscape Narratives at the National Museum of Australia' Journal of Australian Studies, (83) 105-20.

Windschuttle, K. (2001) 'How Not to Run a Museum - People's History at the Postmodern Museum' Quadrant 45 (9) 11-19

Young, J.E. (2000) At Memory's Edge-After Images of the Holocaust in Contemporary Art and Architecture Yale University Press, London

Received $1^{\text {st }}$ November 2005

Finally Accepted 20th ${ }^{t}$ September 2006

* Uros Cvoro completed his PhD at the Centre for Contemporary Art and Politics, University of NSW, Sydney. His research interest is in the relationship of contemporary nationalism and museology. He has published and presented at conferences both in Australia and internationally.

Address:

2/24 Noble Street, Allawah

2218 NSW

Australia

Telephone (02) 95877702

email: ucvoro@hotmail.com 